\title{
Water retention behaviour of compacted bentonites: experimental observations and constitutive model
}

\author{
Anne-Catherine Dieudonne ${ }^{1,2,{ }^{*}}$, Claude Gatabin ${ }^{3}$, Jean Talandier $^{4}$, Frédéric Collin $^{1}$ and Robert Charlier ${ }^{1,{ }^{*}}$

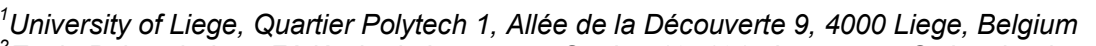

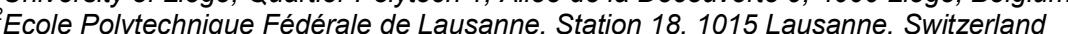 \\ Commissariat à l'énergie atomique et aux énergies nouvelles

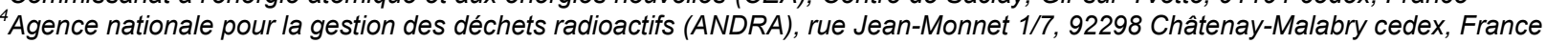

\begin{abstract}
Bentonite-based materials are studied as potential barriers for the geological disposal of radioactive waste. In this context, the hydro-mechanical behaviour of the engineered barrier is first characterized by free swelling conditions followed by constant volume conditions. This paper presents an experimental study conducted in order to characterize the water retention behaviour of a compacted MX-80 bentonite/sand mixture. Then, based on observations of the material double structure and the water retention mechanisms in compacted bentonites, a new water retention model is proposed. The model considers adsorbed water in the microstructure and capillary water in the aggregate-porosity. The model is calibrated and validated against the experimental data. It is used for better understanding competing effects between volume change and water uptake observed during hydration under free swelling conditions.
\end{abstract}

\section{Introduction}

The water retention capacity of compacted bentonites is one of the fundamental properties required for predicting the behaviour of unsaturated engineered barriers. In the context of deep geological repositories for nuclear waste, bentonite-based materials are generally manufactured and emplaced at their hygroscopic water content. Under repository conditions, the engineered barrier experiences hydration from the surrounding geological formation. Because of the existence of unavoidable technological gaps, the periphery of the engineered barrier swells under free conditions first. During this stage, technological gaps are progressively filled by bentonite and the effective density of the buffer decreases. When contact between the geological formation and the engineered barrier is reached, the global volume constraints imposed to the bentonite buffer are close to constant volume conditions and a swelling pressure develops on the gallery wall. The objective of the engineered barrier is to form a tight contact with the surrounding formation and to create a zone of low permeability that is able to limit water flow around the excavated galleries, thereby delaying the release of radionuclides to the biosphere.

Because of the evolution of the volume constraints during the hydration process of the bentonite buffer, a good characterization of the material under both free and restricted swelling is required. To date, few experimental studies have investigated both volumetric and water retention behaviours of compacted bentonite with the aim of obtaining suction - degree of saturation relationships [1-4].

*Corresponding authors: anne-catherine.dieudonne@epfl.ch, Robert.charlier@ulg.ac.be

\section{Material and methods}

\subsection{Material and sample preparation}

The material used in the investigation is a mixture of Wyoming MX-80 bentonite and quartz sand with a respective proportion of $7 / 3$ in dry mass. The MX- 80 bentonite contains $92 \%$ of montmorillonite and other minerals including quartz and feldspars [5]. The solid density of MX-80 bentonite is $2.78 \mathrm{Mg} / \mathrm{m}^{3}$ and that of the quartz sand is $2.65 \mathrm{Mg} / \mathrm{m}^{3}$.

The initial water content of the bentonite/sand mixture was $7.08 \%$. Compacted samples were prepared by uniaxial static compaction $(57 \mathrm{~mm}$ in diameter, $12 \mathrm{~mm}$ in height) to a target dry density of $2.0 \mathrm{Mg} / \mathrm{m}^{3}$. This dry density was selected in order to reach a swelling pressure of about $7 \mathrm{MPa}$ in the PGZ2 in situ experiments performed by ANDRA in its underground research 
laboratory, accounting for $12 \%$ of technological gaps. The vertical net stress required to reach the target dry density was about $80 \mathrm{MPa}$. For this compaction pressure, the optimum water content is about $8 \%$, so that the samples used in the investigation are compacted on the dry side of the optimum (although not far). The initial characteristics of the samples are presented in Table 1.

Table 1. Initial characteristics of the samples used for the determination of the water retention properties.

\begin{tabular}{|c|c|}
\hline Compaction pressure & $\sim 80 \mathrm{MPa}$ \\
\hline Dry density & $2.0 \mathrm{Mg} / \mathrm{m}^{3}$ \\
\hline Void ratio & 0.37 \\
\hline Water content & $7.08 \%$ \\
\hline Degree of saturation & $52.25 \%$ \\
\hline
\end{tabular}

\subsection{Experimental methods}

Water retention curves of the compacted samples were determined under both constant volume and free swelling conditions by using the vapour equilibrium technique. The experiments were performed in the Laboratoire d'étude du comportement des bétons et argiles (LECBA) of the CEA in Saclay, France. After compaction, the samples were carefully removed from the compaction mould and either transferred to a constant volume cell (having the same diameter as the compaction cell) for the measurement of the water retention curve under isochoric conditions, or placed in a glass Petri dish for the determination of the sorption curve under free swelling conditions. Constant volume cells were specially designed for the measurement of the water retention curve under isochoric conditions (Figure 1). Each cell includes a titanium containment ring and two stainless steel porous discs put on both faces of the compacted sample and allowing vapour exchanges. Two perforated flanges hold the entire assembly.

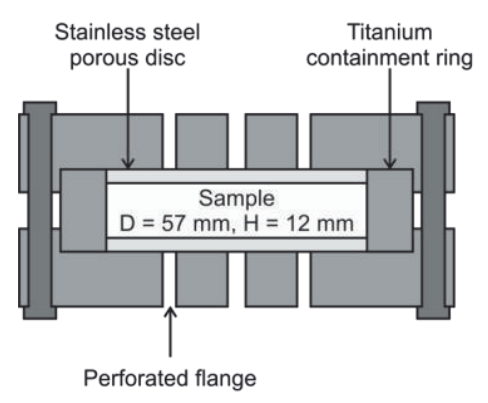

Figure 1. Constant volume cell for water retention curve determination.

All samples were placed in desiccators in which the relative humidity was controlled by using different saturated saline solutions. For the purpose of the experiment, the desiccators were placed within an environmentally controlled room with a temperature of $20^{\circ} \mathrm{C}\left(+/-0.2^{\circ} \mathrm{C}\right)$. At the end of the test, the mass of each sample was measured and the gravimetric water content was determined by oven drying at $105^{\circ} \mathrm{C}$. In addition, the heights and diameters of the samples wetted under unconfined conditions were measured with a precision calliper. Details on the experimental protocol can be found in [4].

\section{Experimental results}

Figure 2 presents the water retention curves obtained under constant volume and free swelling conditions, expressed in terms of water content. At high suctions (above around $10 \mathrm{MPa}$ ), the water content appears to be relatively independent of the volume constraints. In the high suction range, water is indeed essentially stored by adsorption at the surface of the clay particles. Therefore water uptake is mainly controlled by the physicochemical properties of the clay minerals, in particular smectite, and is independent of the current void ratio. On the contrary, in the lower suction range, bentonite swelling affects the water storage capacity of the material [6-12]. The water content reached under free swelling conditions at suction of $3 \mathrm{MPa}$ is much higher than it is under prevented swelling (25.3\% compared to $14.8 \%)$.

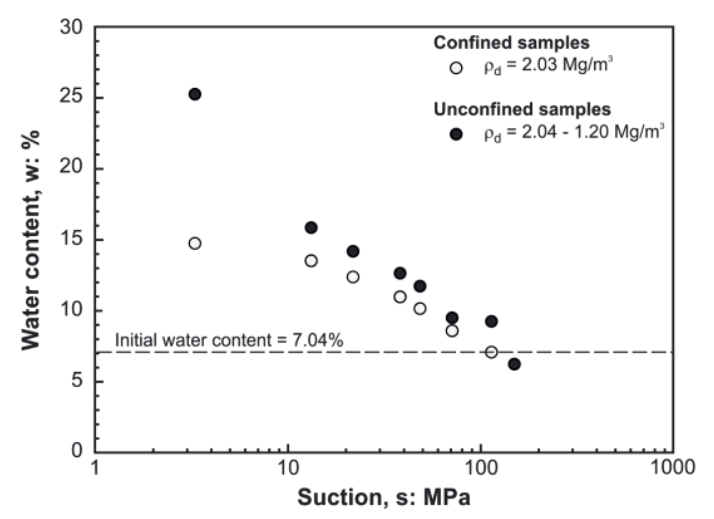

Figure 2. Water retention curves expressed in terms of water content versus suction.

The experimental data presented in Figure 2 can be expressed in terms of degree of saturation. As observed in Figure 3, the imposed volume constraint significantly impacts the water retention behaviour of compacted bentonite-based materials. For samples wetted under isochoric conditions, hydration led to an increase of the degree of saturation. On the contrary, the decrease of suction did not significantly impact the degree of saturation of the samples wetted under free conditions.

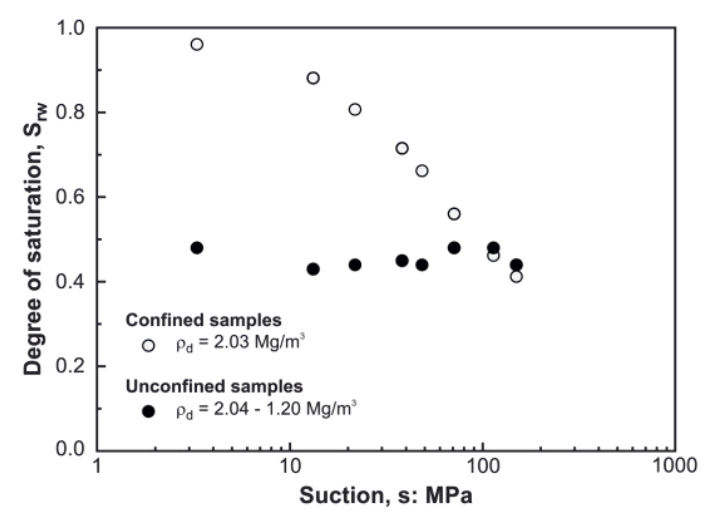

Figure 3. Water retention curves expressed in terms of degree of saturation versus suction. 
This observation is a direct consequence of the important hydro-mechanical coupling in compacted bentonites. Indeed, hydration under unconfined conditions is associated with both an increase in the water content and an increase of the sample volume.

\section{Water retention model}

Water retention models have traditionally been formulated as a unique relationship between suction and the degree of saturation or water content $[13,14]$. If this approach has been successfully applied for granular soils and low activity clay materials, it cannot describe accurately the water retention behaviour of highly expansive materials such as bentonites. Indeed, in the case of compacted bentonites, the material swells significantly upon wetting, resulting in important changes in dry density. Consequently, the dependency of the water retention curve on the dry density of the material is a major issue and explains why classical water retention models have failed in describing the water retention properties of expansive materials. In the last years, a large number of constitutive models have been proposed to tackle the effect of dry density on the water retention behaviour [see for instance 9,15-18]. However, the particularity of expansive clays such as bentonite is their very important volume changes along wetting or drying paths.

Compacted bentonite-based materials are characterized by an aggregated structure which can be observed by mercury intrusion porosimetry or environmental scanning electron microscopy, among others. Aggregates are clusters or clay particles and retain water essentially by adsorption (in the micropores, which include inter-particle pores and interlayer spaces). They are separated by inter-aggregate pores (also called macropores) in which the water retention mechanism may be assimilated to capillary (Figure 4).

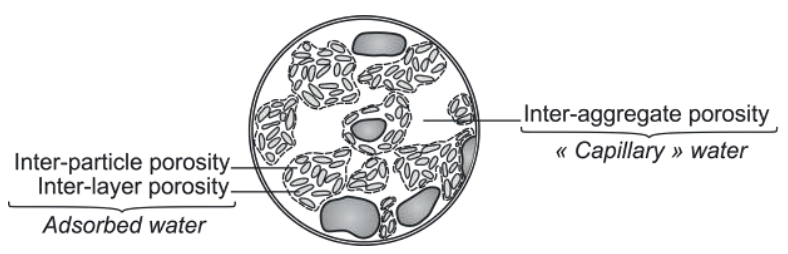

Figure 4. Conceptual representation of the structure of compacted bentonite-based materials and the different water retention mechanisms.

Accordingly, the total water ratio $e_{w}$ (defined as the volume of water over the volume of solids) contains two contributions from the microstructure and macrostructure

$$
e_{w}=e_{w m}+e_{w M}
$$

where $e_{w m}$ represents the water adsorbed in the microstructure and $e_{w M}$ the water stored in the interaggregate pores or macrostructure.

Water retention models for both the microstructure and the macrostructure should be defined. Moreover, the structure created upon compaction is strongly influenced by hydromechanical loads [6,7]. The evolution of the microstructure during wetting or drying should therefore be considered.

\subsection{Microstructural water retention model}

Water in the microstructure is mainly stored by adsorption. In this paper, a generalized expression of Dubinin's isotherm is used [19]. The microstructural water ratio $e_{w m}$ is given by

$$
e_{w m}=e_{m} \exp \left[-\left(C_{a d s} s\right)^{n_{a d s}}\right]
$$

where $e_{m}$ is the microstructural void ratio (volume of micropores over volume of solids), and $C_{a d s}$ and $n_{a d s}$ are material parameters.

\subsection{Macrostructural water retention model}

The van Genuchten water retention model [13] is extended to represent water retention in the macropores. It is expressed as

$$
e_{w M}=\left(e-e_{m}\right)\left[1+\left(\frac{s}{\alpha}\right)^{n}\right]^{-m}
$$

where $\left(e-e_{m}\right)$ represents the macrostructural voids ratio (volume of macropores over volume of solids), $\alpha$ is a parameter related to the air-entry pressure, and $m$ and $n$ are material parameters. In order to represent the influence of bentonite structure on the air-entry value, the parameter $\alpha$ is assumed to depend on the macrostructural void ratio. The following law is adopted

$$
\alpha=\frac{A}{e-e_{m}}
$$

where $A$ is a parameter of the model.

\subsection{Microstructure evolution model}

The microstructure of compacted clayey soils is known to evolve along hydromechanical stress path. In particular, good correlations have been found between the microstructural void ratio and the water content. In this work, the evolution law of the microporous volume with water content has been introduced through the equation proposed by [20]

$$
e_{m}=e_{m 0}+\beta_{0} e_{w}+\beta_{1} e_{w}^{2}
$$

where $\beta_{0}$ and $\beta_{1}$ are two parameters quantifying aggregate swelling and $\mathrm{e}_{\mathrm{m} 0}$ is the intra-aggregate void ratio for the dry material. Note that such a relationship, relating the microstructural void ratio to the total water content (not the microstructural water content), is justified by the fact that, in compacted bentonites, the capillary water represents only a small fraction of the total water stored. The parameters of the model for the compacted mixture were calibrated based on experimental pore size distributions presented in $[21,22]: \mathrm{e}_{\mathrm{m} 0}=0.29, \beta_{0}=0.1$ and $\beta_{1}=0.18$. 


\section{Validation of the water retention model}

Figure 5 presents the calibration of the water retention model on the experimental water retention curve determined under confined conditions. The parameters used for the model are: $C_{a d s}=0.0053 \mathrm{MPa}^{-1}, n_{a d s}=0.79$, $A=0.2, n=3$ and $m=0.15$.

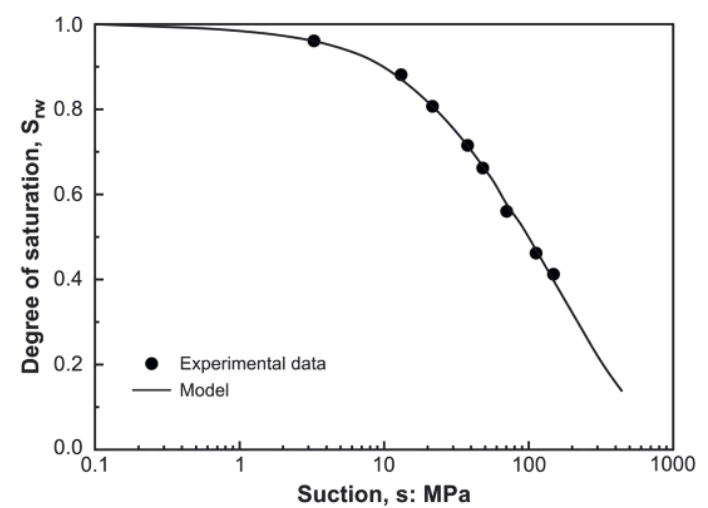

Figure 5. Comparison between experimental data and model predictions. Wetting path under confined conditions.

The model is validated against experimental data on wetting paths under unconfined conditions. Figure 6 presents the evolution of the degree of saturation of the compacted mixture upon wetting under free swelling conditions. In this case, the values of void ratio determined experimentally were used to compute the degree of saturation. The model remarkably succeeds in tracking the evolution of the degree of saturation over the whole range of investigated suctions. For the sake of completeness, the water retention curves predicted for the different current void ratios are also represented. As observed in Figure 6, an important decrease in the air entry pressure is associated with the important swelling of the material.

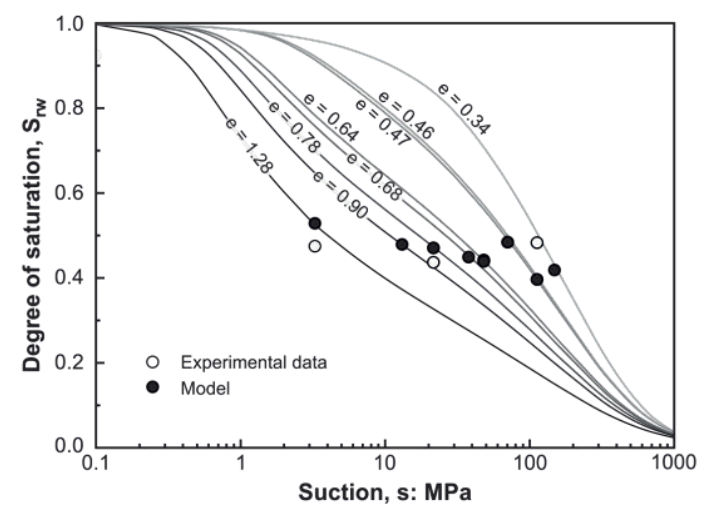

Figure 6. Comparison between experimental data and model predictions. Wetting path under unconfined conditions. Experimental data and model predictions are superposed at suctions of $150 \mathrm{MPa}, 71 \mathrm{MPa}, 48 \mathrm{MPa}, 38 \mathrm{MPa}$ and $13 \mathrm{MPa}$.

In order to better understand the mechanisms behind the competing effects, the evolution of the total, microstructural and macrostructural void ratios upon wetting is analysed. Under confined conditions, the total void ratio is constant while wetting leads to an increase of the microstructural void ratio (following the evolution predicted by Equation (5)), hence a decrease of the macroporous volume (Figure 7).

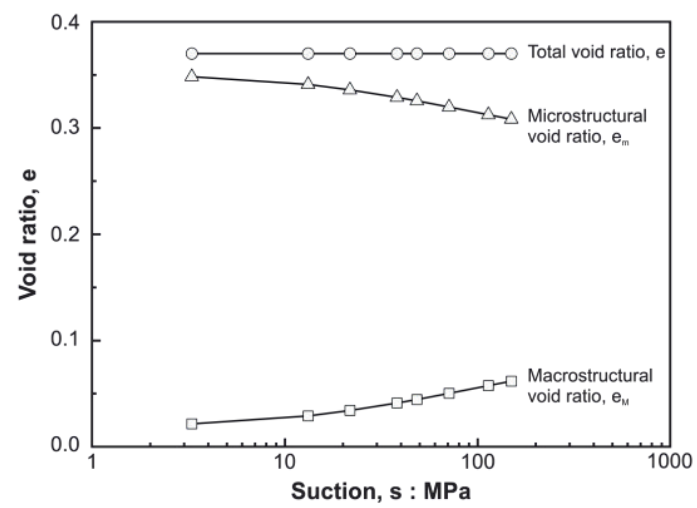

Figure 7. Model predictions for the evolution upon wetting of the total, microstructural and macrostructural void ratios. Wetting under confined conditions.

On the other hand, when the sample is wetted under free swelling conditions, the overall swelling of the sample is more important than the development of the microstructure (Figure 8). The increase in the total void ratio is indeed more significant than the micropores swelling. An increase in the inter-aggregate volume is therefore predicted. Unfortunately, no experimental information on the evolution of pore size distributions upon wetting under unconfined conditions is available in the literature.

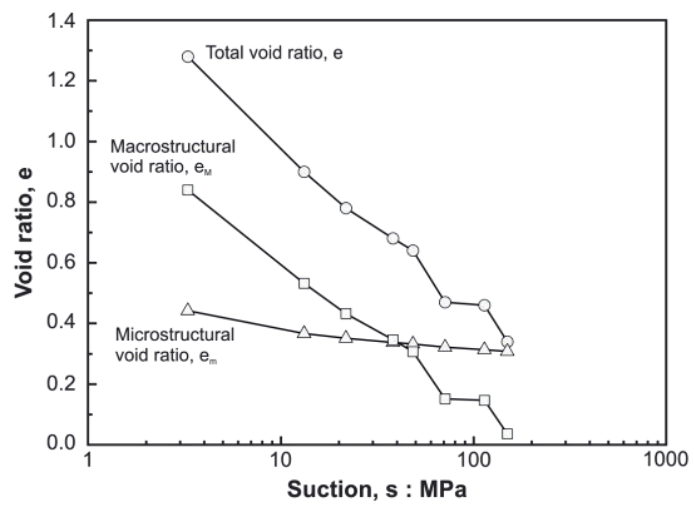

Figure 8. Model predictions for the evolution upon wetting of the total, microstructural and macrostructural void ratios. Wetting under unconfined conditions.

\section{Conclusions}

Water retention curves under constant volume and free swelling conditions were determined. For high suction values, the wetting branch in terms of water ratio appeared to be void ratio independent. On the contrary, the boundary conditions significantly influenced the water uptake capacity of the bentonite/sand mixture in the lower suction domain. The quantity of water stored under free swelling conditions is much higher than under constant volume. 
In terms of degree of saturation, the samples at high initial density wetted under free volume conditions do no exhibit significant changes of degree of saturation. This is explained by the important competing effects of bentonite swelling and water uptake along wetting paths, as a consequence of strong hydro-mechanical coupling in compacted bentonites. Indeed the high-density samples exhibit important swelling, i.e. mechanical drying when suction decreases.

In order to complement the interpretation and model the experimental results, a water retention model was developed. This model explicitly takes into account the aggregated and evolving double structure of compacted bentonite-based materials. The model is calibrated and validated against the experimental data. The model succeeds in reproducing the stability of the degree of saturation upon wetting under unconfined conditions. The model provides a better understanding of the influence of the complex hydromechanical processes on the water retention curve. The influence of the microstructure evolution is highlighted.

While classical water retention models relating suction to the degree of saturation are generally used in numerical modelling (their parameters being determined from constant volume water retention curves), they are not able to represent the observed behaviour. In this case, the predicted degree of saturation of a bentonite plug under in situ conditions can be considerably overestimated if technological voids are important and not taken into account in modelling. A good representation of the water retention properties of compacted bentonites is thus a fundamental issue.

\section{References}

1. P. Delage, M. Howat, Y.J. Cui. The relationship between suction and swelling properties in a heavily compacted unsaturated clay. Engineering Geology 50, 31-48 (1998)

2. A. Dueck. Laboratory results from hydro-mechanical tests on a water unsaturated bentonite. Engineering Geology 97 (1-2), 15-24 (2008)

3. M. Ajdari, G. Habibagahi, F. Masrouri. The role of suction and degree of saturation on the hydromechanical response of a dual porosity silt-bentonite mixture. Applied Clay Science 83-84, 83-90 (2013)

4. C. Gatabin, J. Talandier, F. Collin, R. Charlier, A.C. Dieudonné. Competing effects of volume change and water uptake on the water retention behaviour of a compacted MX-80 bentonite/sand mixture. Applied Clay Science 121-122, 57-62 (2016)

5. A.M. Tang, Y.J. Cui, T.T. Le. A study on the thermal conductivity of compacted bentonites. Applied Clay Science 41(3-4), 181-189 (2008)

6. E. Romero, A. Gens, A. Lloret. Water permeability water retention and microstructure of unsaturated compacted Boom Clay. Engineering Geology 54, 117-127 (1999)

7. C. Loiseau, Y.J. Cui, P. Delage. The gradient effect on the water flow through a compacted swelling soil. In: J.F.T. Juca, T.M.P. de Campos, F.A.M. Marinho
(Eds), Unsaturated Soils, Proceedings of the $3^{\text {rd }}$ International Conference on Unsaturated Soils (UNSAT2002), Recife, Brazil, 395-400 (2002)

8. M.V. Villar. Water retention of two natural compacted bentonites. Clays and Clay Minerals 55(3), 311-322 (2007)

9. E. Romero, G. Della Vecchia, C. Jommi. An insight into the water retention properties of compacted clayey soils. Géotechnique 61(4), 313-328 (2011)

10. S.S. Agus, Y.F. Arifin, S. Tripathy, T. Schanz. Swelling pressure - suction relationship of heavily compacted bentonite-sand mixtures. Acta Geotechnica 8(2), 155-165 (2013)

11. A. Seiphoori, A. Ferrari, L. Laloui. Water retention behaviour and microstructural evolution of MX-80 bentonite during wetting and drying cycles. Géotechnique 64(9), 717-734 (2014)

12. G. Della Vecchia, A.C. Dieudonne, C. Jommi, R. Charlier. Accounting for evolving pore size distribution in water retention models for compacted clays. International Journal of Numerical and Analytical Methods in Geomechanics 39(7), 702723 (2015)

13. M.T. Van Genuchten. A closed-form equation for predicting the hydraulic conductivity of unsaturated soils. Soil Science Society of America Journal 44(5), 892-898 (1980)

14. R.H. Brooks, A.T. Corey. Hydraulic properties of porous media. Hydrological papers (Colorado State University) 3 (1964)

15. D.A. Sun, D. Sheng, L. Xiang, S.W. Sloan. Elastoplastic prediction of hydro-mechanical behaviour of unsaturated soils under undrained conditions. Computers and Geotechnics 35(6), 845852 (2008)

16. D. Masin. Predicting the dependency of a degree of saturation on void ratio and sucion using effective stress principle for unsaturated soils. International Journal for Numerical and Analytical Methods in Geomechanics 34, 73-90 (2010)

17. S. Salager, M. Nuth, A. Ferrari, L. Laloui. Investigation into water retention behaviour of deformable soils. Canadian Geotechnical Journal 50, 200-208 (2013)

18. D. Gallipoli, A.W. Bruno, F. D’Onza, C. Mancuso. A bounding surface hysteretic water retention model for deformable soils. Géotechnique 65(10), 793-804 (2015)

19. M.M. Dubinin, L.V. Radushkevich. Equation of the characteristic curve of activated charcoal. Proceedings of the academy of Sciences, Physical Chemistry Section, USSR 55, 331-333 (1947)

20. A.C. Dieudonne, S. Levasseur, R. Charlier, G. Della Vecchia, C. Jommi. A water retention model for compacted clayey soils. In: S Pietruszcak, G.N. Pande (Eds.) Computational Geomechanics COMGEO III, Proceeding of the $3^{\text {rd }}$ International Symposium on Computational Geomechanics, 23-31 (2013)

21. Q. Wang, A.M. Tang, Y.J. Cui, P. Delage, J.D. Barnichon, W.M. Ye. The effects of technological voids on the hydromechanical behaviour of 
compacted bentonite-sand mixture. Soils and Foundations 53(2), 232-245 (2013)

22. S. Saba, P. Delage, N. Lenoir, Y.J. Cui, A.M. Tang, J.D. Barnichon. Further insight into the microstructure of compacted bentonite-sand mixture. Engineering Geology 168, 141-148 (2014) 